\title{
A review on power quality challenges in renewable Energy grid integration
}

\author{
Sonali N. Kulkarni ${ }^{*}$, Prashant Shingare ${ }^{\ddagger}$ \\ †Electronics \& Telecommunication Engineering, Rajiv Gandhi Institute of Technology, Versova, Andheri (W), Mumbai, Maharashtra, India \\ ‡Emerson Network Power India Pvt Ltd, NITCO Business park, Wagle Industrial Estate, Thane (W), Maharashtra, India.
}

Accepted 01 Sept 2016, Available online 02 Sept 2016, Vol.6, No.5 (Oct 2016)

\begin{abstract}
Over the past three decades global energy consumption has increased drastically due to industrialization, automation of various systems and rise in utilization of domestic machine appliances. In order to fulfill the increasing power demand, the power sector is looking for renewable energy sources as an alternative to conventional sources. The Renewable Energy is generated using distributed generation. Renewable Energy is unpredictable, non storable and intermittent due to varying nature of natural resources. Today's biggest challenge is to accommodate excess generation of Renewable Energy into existing power system without disturbing power quality. The power quality and hence stability of power system gets affected due penetration of Renewable Energy and loading effect of transmission lines corresponding to small disturbances. Therefore, it is a challenging task to maintain healthy, reliable and smart electrical power transmission and distribution system. This paper deals with the power quality parameters, challenges in Renewable Energy grid integration and the possible solutions to maintain power quality.
\end{abstract}

Keywords: Distributed Generation, Frequency variation, Grid Integration, Grid Stability, Harmonic Distortion, Low Voltage Ride Through, Micro Grid, Power Quality, Renewable Energy, Smart Grid, Voltage Sag.

\section{Introduction}

Over the past three decades, global energy generation and consumption have accelerated to unprecedented degrees. In India a large amount of electricity is used for residential, commercial and industrial processes applications every day. Today's increasing power demand, power crises due to scarcity of conventional sources and impact of conventional source on environment are some of the reasons for paying more attention towards renewable energy sources. The renewable energy sources like wind and solar offers alternative sources of energy, which are in general pollution free, technologically effective, environmentally sustainable and provides electricity without giving rise to carbon dioxide emissions (Shafiullah, et al, 2013). However, most of the existing grid networks consisting of transmission and distribution networks are not capable to handle excess penetration of renewable energy. In power system most of the complexities occur due to the interconnections of different types of power generators, transmission lines, transformers, and varying nature of different loads (Sandhu and Thakur, 2014). The stability and power quality of power system gets affected due interconnection of unpredictable

*Corresponding author Sonali N. Kulkarni is a Research Scholar and Prashant Shingare is working as Director of Wind Energy nature of different generators, fluctuating load, loading effect of transmission lines etc. Therefore, it is very challenging to maintain reliable and healthy power system irrespective of different uncertainties.

The rest of the paper is organized as follows: Section 2 reviews background and customers of power quality. In Section 3 different power quality parameters are discussed. The cost of poor power quality is reviewed in section 4. The possible solutions to power quality problems are discussed in Section 5 followed by the conclusion.

\section{Background}

In order to fulfill the increasing demand of electricity, power sector is using several renewable energy sources like wind energy, photovoltaic energy, wave energy, tidal energy etc. along with the conventional sources for power generation. Renewable energy generation is unpredictable and intermittent in nature; it is therefore a challenging task to integrate renewable energy resources into the power grid without affecting power quality. In power system most of the complexities occur due to the interconnections of various types of power generators, transmission lines, transformers, and load (Sandhu and Thakur, 2014). The stability of power grid gets affected due to integration of renewable energy, generated in 
distributed manner. Distributed Generation (DG) is used to minimize the losses and loading effect of transmission lines. The distributed generation is the recent trend of distribution network service providers, in which significant power generation is done near the distribution level. Integration of distributed generation causes bidirectional power flow among the network, which reduces the capacity of feeder and transmission line (Enslin, 2010). The other benefits of distributed generation include the reduction of power loss, better voltage support, peak shaving and the improvement of overall efficiency, stability and reliability of the power system (Enslin, 2010), (Roy, et al, 2011). The renewable energy generation is unpredictable and intermittent in nature hence; it is a challenging task to integrate renewable energy resources into the power grid without affecting power quality. The challenges and issues associated with the grid integration of various renewable energy sources particularly wind energy conversion systems are described in terms of power quality (PQ) (Ackerman, 2005).

\subsection{Power Quality Customers}

Power quality sensitive customers are grouped into three categories as (Darrow and Headman, 2005):

1. Digital customers: The organizations like banks, stock market, airline reservation systems and corporate offices that rely heavily on data storage and retrieval, data processing, or research and development, need to protect computers, peripherals, and computer cooling equipment. The companies involved in communications facilities like television and radio stations, internet service providers, cellular phone stations, and satellite communication systems need electricity for their computers, peripherals and broadcasting equipments to ensure smooth operation of the systems.

2. Continuous Process Industries: The continuous product manufacturing industries like chemical, petroleum, rubber, plastic etc., require continuous supply of electricity during manufacturing to ensure product quality and protect their equipments and computers.

3. Other Essential Services: This includes other manufacturing industries, transportation facilities, water and waste water treatment, and gas pipelines.

\subsection{Power Quality}

Power quality is the term used to describe how closely the electrical power delivered to customers corresponding to the appropriate standards which operates end user's equipment correctly. Power Quality is a measure of ideal power supply. Power Quality is defined as any power problem manifested in voltage, current, and/or frequency deviations that results in the failure and/or mal-operation of end users equipment (Velayutham, 2015). Due to poor power quality individual consumer suffers, industry suffers which affects the economy of nation (Velayutham, 2015). The penetration of renewable energy into existing power grid is increasing exponentially. Due to the high penetration level of renewable energy like wind, solar etc, in distribution network, the power sector is concerned about the stability of utility grid, power quality (PQ) and voltage regulation (Sandhu and Thakur, 2014). The issues of power quality are of importance to wind energy as an individual unit is of large capacity up to few Megawatts. Further, such a large capacity wind power generator is feeding into distribution circuits, with customers connected in close proximity. The fluctuations in wind speed have a negative impact on power generation, hence on stability and power quality of power system (Singh, et al, 2011). The causes of poor power quality (Velayutham, 2015), (Shingare, 2014) are:

a. Intermittent or unpredictable nature of Renewable Energy generators: The normal operation of wind generator gets affected due to variation in availability renewable sources, adjustable speed drives etc.

b. Variable or Nonlinear loads: The power quality affects due to abrupt changes in load such as start / stop of large motor loads, arc furnaces, lightning, switching devices, traction drives etc.

c. Grid Faults: These are the problems related to grid infrastructure due to ageing of grid network, problems with transmission lines, insulators etc.

\section{Power quality parameters}

The quality of power in distribution grid gets affected due to different types of disturbances at generator side and load side which lead to variation in performance parameters of electrical supply. The parameters of power supply like voltage, frequency are to be monitored continuously. The variation in voltage, frequency and noise level leads to poor power quality. The various parameters of power quality are (Velayutham, 2015), (Almeida, et al, 2013):

1. Voltage sags and swells: Voltage sag is a short duration phenomena in power system in which RMS voltage magnitude decreases between 10 and 90 percent of the nominal RMS voltage at the power frequency, for durations of 0.5 cycle to 1 minute as shown in Fig.1-A.

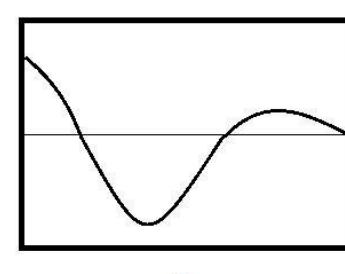

A

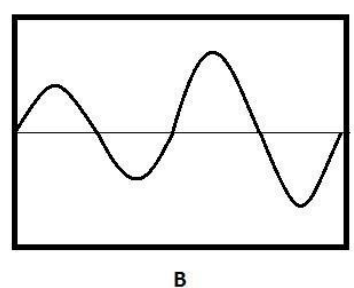

Fig. 1 A: Voltage sag, B: Voltage swell (Almeida, et al, 2013) 
The voltage sag occurs due to faults on the transmission or distribution network (most of the times on parallel feeders). It also occurs due to faults in consumer's installation, connection of heavy loads and startup of large motors (Tejavoth, et al, 2013).

The voltage swell is momentary or sudden increase of the RMS voltage, at power frequency outside the normal tolerances, with duration of more than one cycle and typically less than a few seconds refer Fig.1B. It occurs due to start/stop of heavy loads, badly dimensioned power sources, badly regulated transformers (mainly during off-peak hours) (Almeida, et al, 2013).

2. Harmonic Distortion: Voltage and current harmonics and sub-harmonics: It corresponds to the supply voltage or current waveforms of non-sinusoidal shape. The waveform corresponds to the sum of different sine waves with different magnitude and phase, having frequencies that are multiples of power system frequency as shown in Fig.2-A. Harmonic distortion causes due different types of nonlinear loads like arc furnaces, welding machines, rectifiers, switched mode power supplies, data processing equipment etc. A common term that is used in relation to harmonics is called as THD or Total Harmonic Distortion (Velayutham, 2015). The term THD is used to describe voltage or current distortion and is calculated using Eq (1) (Velayutham, 2015), (Almeida, et al, 2013):

$\%$ T H D $=\sqrt{\mathrm{I}\left(\mathrm{D}_{1}\right)^{2}+\mathrm{I}\left(\mathrm{D}_{2}\right)^{2}+\ldots}$.

Where I(Dn) is the magnitude of the $\mathrm{n}$ th harmonic as a percentage of the fundamental (individual distortion). The THD is zero for a perfectly sinusoidal wave. It increases indefinitely as the wave form distortion increases. A THD of 5 percent is commonly cited as the border line between high and low distortion for distribution circuits (Velayutham, 2015).

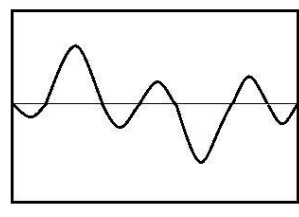

A

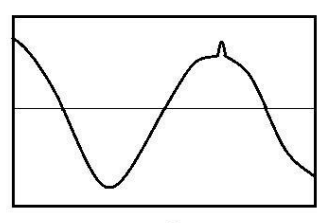

B
Fig. 2 A: Harmonic Distortion, B: Voltage spike (Almeida, et al, 2013)

3. Voltage Spike: Voltage spike is nothing but a very fast increase in voltage (maximum voltage in the range of thousands) within duration of several microseconds to few milliseconds as shown in Fig. 2-B. The voltage spike causes due to lightening, switching of capacitors, and disconnection of heavy loads. Sometimes, it may damage the electronic components, insulation materials and may cause electromagnetic interference.

4. Voltage Interruptions: A voltage interruption (IEEE Std. 1159), supply interruption (EN 50160), or just interruption (IEEE Std.1250) is a condition in which the voltage at the supply terminals is close to zero. As defined in IEEE, Close to zero means lower than 10 percent of its nominal supply (IEEE Std.1159) (Tejavoth, et al, 2013). The Voltage interruptions can be for short duration or long duration. They are normally initiated due to tripping or failure of protection devices. If the voltage supply interruption occurs from few milliseconds to one or two seconds, it is called short duration interruption as shown in Fig. 3A (Almeida, et al, 2013). If the supply voltage interruption persists for greater then one or two seconds, it is called long duration interruption shown in Fig.3-B (Almeida, et al, 2013).
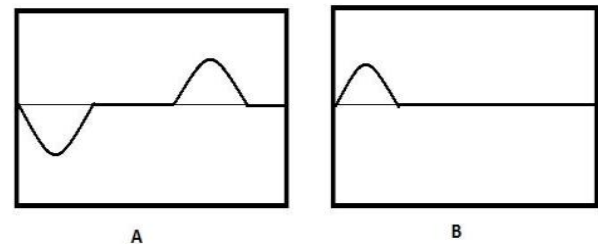

Fig. 3 A: Voltage Interruption (Short duration), B: Volt-age Interruption (Long duration) (Almeida, et al, 2013)

5. Voltage unbalance: A voltage unbalance in a three phase system means the magnitudes of three voltages are different and the phase difference between them is not equal to 120 degree refer Fig.4-A. It causes due to unbalanced load in three phase system. The most affected loads are three phase induction machines (Almeida, et al, 2013).
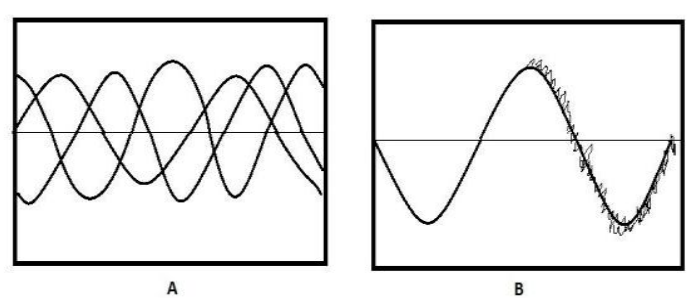

Fig. 4 A: Voltage Unbalance, B: Noise (Almeida, et al, 2013)

6. Noise: Noise is superimposing of high frequency signal on the power supply waveform as shown in Fig.4-B. There are various causes or sources of noise in the power system like electromagnetic interference, radiations due to welding machines and furnaces etc. Usually noise is not destructive but it may cause data processing errors and disturbance to sensitive equipments (Almeida, et al, 2013).

7. Flickers and fluctuations: During normal operation, wind turbines produce a continuously variable output power as result of fluctuation in wind speed (Ackerman, 2005). The random nature of wind resources, in the wind farm generates fluctuating electric power. The fluctuating electric power when injected to the power grid leads to the variation of wind farm terminal voltage due to system impedance. 
This power disturbance propagates into the power systems and can produce a phenomenon known as flicker, which consists of fluctuations in the illumination level caused by voltage variations. The oscillation of RMS voltage value, amplitude modulated by a signal with frequency of 0 to $30 \mathrm{~Hz}$ (Almeida, et al, 2013).

8. Frequency deviations: Frequency deviation is the variation of relatively small frequency value around its nominal or ideal value. Supply frequency is one of the most critical parameter of the power system. Controlling supply frequency is one of the most challenging part of power system (Velayutham, 2015). There are various reasons for supply frequency deviation.

9. Power factor: The concept of power factor originated from the need to quantify how efficiently a load utilizes the current that it draws from an $\mathrm{AC}$ power system. The true power factor at the load is defined as the ratio of average power to apparent power. In AC (sinusoidal) supply with linear load, it is called displacement power factor. With a non sinusoidal supply, the true power factor is influenced by current harmonics and a distortion power factor is included apart from displacement power factor. In order to improve power factor in a harmonic environment filter associated capacitors are used (Velayutham, 2015). The basic technical challenge comes from the variability of wind and solar power which affects the load, generation balance, varying demand for reactive power and voltage stability.

\section{Cost of poor power quality}

The costs of power quality problems are highly dependent of several factors, like the business area, sensitivity of the equipment used in the facilities and market conditions etc. A huge financial loss occurs due to power quality problems. Generally all the electricity consumer loads are not sensitive to power quality variations (Darrow and Headman, 2005). Therefore, the type of load will depend on size of the sensitive load with respect to the entire load (Darrow and Headman, 2005). The costs related to a power quality disturbance can be divided in:

- Direct costs: The costs that can be directly related to the power quality disturbance. These costs include the damage of equipments in continuous process industry, loss of production, loss of raw material, salary costs during nonproductive period and restart costs. Some power quality disturbances do not stop production, but may have other costs associated, like reduction of equipment efficiency, reduction of equipment life etc.

- Indirect costs: These costs are very hard to evaluate. The cost, an organization has to pay or loss of further orders due to delay in material delivery caused because of power quality disturbances. All the preventions taken to avoid power quality problems are considered as indirect cost.
- Non-material inconvenience: These are some of the inconveniences caused due to power failure or disturbance and cannot be expressed in money. It is the cost that consumer is willing to pay to avoid or handle such inconveniences (Almeida, et al, 2013).

\section{Solutions to poor power quality}

In power system, the interaction of power generators, transmission, voltage control, and loads at multiple points at the grid leads to temporal supply variations at an individual customer level. The presence of variations in different power quality parameters, discussed in Section 3 are termed as low power quality. The degree to which power is provided to customers without interruptions is termed as reliability (Darrow and Headman, 2005). The various solutions to tackle the problem of poor power quality are discussed in following sections.

\subsection{Micro grid / Smart grid}

Micro grid is an important auxiliary part of the distribution system proposed in America by the Consortium for Electrical Reliability Technology Solutions (CERTS) (Deng and Pei, 2008). They consists of some micro sources and loads which can operate in both islanded and grid connected mode. The advantages of micro-grid systems are flexible installation and the control over active and reactive power separately (Deng and Pei, 2008). Microgid economically provides electricity to critical loads within the micro-grid by integrating and optimizing various sources of energy. Due to integration of various sources reliability is generally improved, because the more sources of electricity generation are available across a wide geographic area. It also provides better power quality and flexibility to the users (Hyden, 2013).

The smart grid is a modern electric power grid infrastructure for enhanced efficiency and reliability through automatic control, high power converters, modern communications infrastructure, advanced sensing and metering technologies. It consists of modern energy management techniques based on the optimization of demand, energy generation and network availability (Gungor, et al, 2011), (NIST, 2010). Smart-grid is used to describe a smart electric power system that uses Information and Communications Technologies (ICT) to optimize electric power generation, distribution to achieve a balance between power generation and demand (Deng and Pei, 2008). The smart grid technology will be play a self regulatory role in power networks and ensures power quality of the network by reducing voltage fluctuation (sag, swell and spikes) and harmonic effects in the network (Shafiullah, et al, 2013).

\subsection{Advanced Technology and Wind Farm Project Planning}


Wind turbines converts kinetic energy present in the wind into electric power. The wind speed varies continuously as a function of time, height geographical location and season. Due to the fluctuating nature of wind speed there is practical limitation for using wind as a source for power generation (Ackerman, 2005). The wind speed fluctuations which occur in the subsecond to minute range are called as turbulent peak. The diurnal peak depends on daily wind speed variations and the synoptic peak depends on changing weather patterns due to seasonal cycles. The turbulent peak may affect the power quality of wind power production. The impact of turbulence on power quality depends very much on the type of turbine technology used. The variable speed wind turbines may absorb short term power variations caused due to wind speed variation by the immediate storage of energy in the rotating masses of the wind turbine drive train. Due to which their power output is smoother than that of strongly grid coupled turbines. Diurnal and synoptic peaks, however, may affect the long term balancing of the power system (Ackerman, 2005), (Shingare, 2014). Due to fluctuations in wind speed, power generated by the turbine also fluctuates. Figure 5 shows the relation between wind speed variation (IMD, 2015) and power generated by a single turbine manufactured by a leading manufacturer.

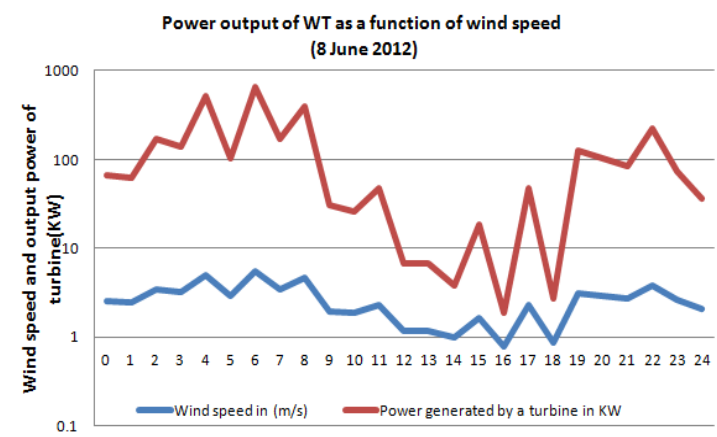

Fig. 5 Wind speed and power generated by a single wind turbine (IMD, 2015)

The literature shows that, in order to reduce the impact of wind speed on power generations and sudden power fluctuations following steps are suitable:

1. Modification in power curve: Some wind turbine manufacturers offer wind turbines with special type of power curve as shown in Fig.6.

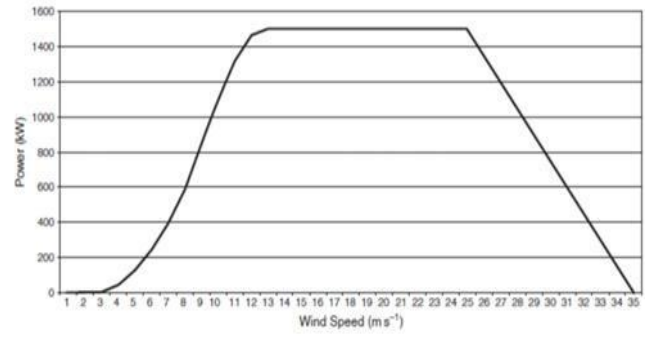

Fig. 6 Modified Power curve (Ackerman, 2005)
In these turbines, instead of a sudden cut off, power generation is reduced step by step with increasing wind speed above cutoff speed (Ackerman, 2005). This certainly reduces the possible negative impacts that very high wind speeds can have on power system operation.

2. Aggregation of wind turbines: The aggregation of wind turbines provides a positive effect on power system operation and power quality (Ackerman, 2005). By increasing the number of wind turbines in the wind farm reduces the impact of the turbulent peak as gusts do not hit all the wind turbines at the same time. Thus there will be less power variation in the resultant output power. Under ideal conditions, the relation between percentage variation of power output and the number of wind generators is given using Eq. (2) (Ackerman, 2005).

$\Delta P o=n^{1 / 2}$

where $\mathrm{n}$ is the number of wind turbine generators.

Thus in order to achieve a significant smoothing effect, the number of wind turbines within a wind farm does not need to be very large. Figure 7 shows the resultant power variation with a change in wind speed (IMD, 2015), during the aggregation of 5 and 10 wind turbines. It is observed that the power fluctuation during the aggregation of ten wind turbines is less than that of five. The resultant power output of 10 wind turbines is smoother as compared to 5 turbines.
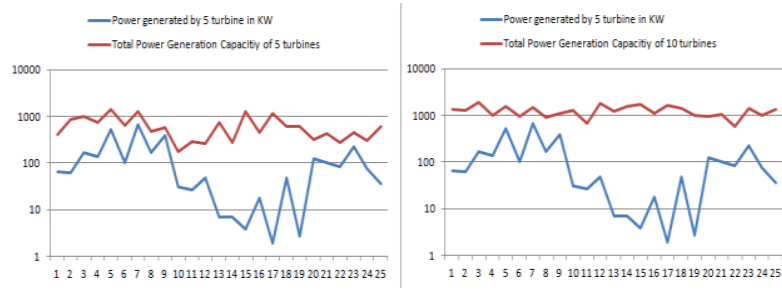

Fig. 7 Total Power generated by aggregation of 5 and 10 Wind Turbines respectively (IMD, 2015)

3. The distribution of wind farms over a wider geographical area: It reduces the impact of the diurnal and synoptic peak significantly as changing weather patterns do not affect all wind turbines at the same time. If changing weather patterns move over a larger terrain, maximum up and down ramp rates are much smaller for aggregated power output from a very large single wind farm.

\subsection{Low Voltage Ride Through (LVRT)}

Low Voltage Ride through (LVRT) or Fault Ride Through (FRT) is defined in the grid codes of different countries. Grid codes are the rules and regulations set by power system operators which need to be obeyed by all power generators in order to get connected with the power grid. In case of wind turbine generators, grid codes ensure power system operators to extend wind generator's grid connection during the grid faults 
(Gehlhaar, 2010). Low Voltage Ride Through (LVRT) describes the grid connection requirement of the wind turbine generating plants when the grid voltage gets temporarily reduced due to a fault or sudden load change (Leao, et al, 2011). During the penetration of wind power, a mismatch is produced between the generated active power and active power delivered to the grid. LVRT requirement helps in the management of this mismatch at the point of common coupling (PCC). In the presence of grid voltage dips, the wind power plants are required to stay connected to the grid and remain operational thereby supporting the grid with reactive power (Malia, et al, 2013). The LVRT requirements guarantee the connection and support of generating plants to the grid during voltage drops. During the voltage drops, the generating plants support the grid by feeding reactive current into network thereby raising the voltage. After the fault clearance, the active power output is increased again to the value prior to the occurrence of the fault, within a specified period of time (Dirksen, 2013). LVRT helps in maintaining voltage stability of a grid connected wind power system by preventing premature tripping of numerous wind generators thus reduces the risk of voltage collapse (Malia, et al, 2013).

\section{Conclusion}

In power system most of the complexities occur due to the interconnections of different types of power generators, transmission line, transformer, and varying nature of load. Therefore, it is challenging to maintain reliable and healthy power system while integrating renewable energy sources with power grid. In this paper we discussed power quality, power quality challenges, it's parameters, various power quality customers, and the cost of poor power quality. Further, we discussed various solutions to address the power quality challenges by incorporating the various methods along with technological advances.

\section{Acknowledgement}

This work was partially supported by Bharati Vidyapeeth College of Engineering, Navi Mumbai. We are thankful to our colleagues for their support and encouragement.

\section{References}

G. Shafiullah, M. Amanullah, A. ShawkatAli, P. Wolfs P. (February 2013), Smart Grid for a Sustainable Future, Smart Grid and Renewable Energy, Scientfic Research, pp. 23-34.

Sandhu M., Thakur T. (2014). Issues, Challenges, Causes, Impacts and Utilization of Renewable Energy Sources Grid Integration. International Journal of Engineering Research and Applications, ISSN : 2248-9622, Vol. 4, Issue 3( Version 1), pp. 636-643.

J. Enslin (July 2010), Network impacts of high pen-etration of photovoltaic solar power systems, IEEE Power and Energy Society General Meeting, pp.1-5.
N. Roy, M. Mahmud, Pota H. (Aug 2011). Impact of high wind penetration on the voltage profile of distribution systems North American Power Symposium (NAPS), pp.11-6.

T. Ackermann, (2005). A book on: Wind Power in Power Systems, Wiley Publication, England, pp. 97-112,169-182.

Darrow K., Hedman B. (December 2005). The Role of Distributed Generation in Power Quality and Reliability, Final Report for New York State Energy Research and Development Authority, 17 Columbia Circle, Albany, New York 12203-6399, pp.1-118.

A.Velayutham, (January 2015), Expert talk on Power Quality (PQ) Issues in smart Grid and Renewable Energy Soures, Ex Member,MERC, at SGRES, CPRI, Bangalore.

M. Singh, Khadkikar V., A. Chandra, . Varma R (January 2011). Grid Interconnection of Renewable Energy Sources at the Distribution Level With Power-Quality Improvement Features, IEEE Transaction on Power Delivery, VOL. 26, NO. 1, pp. 307-315.

C. Tejavoth, M. Trishulapani, V. Rao, Y. Rambabu (July 2013). Power Quality Improvement for Grid Connected Wind Energy System using STATCOM-Control Scheme, IOSR Journal of Engineering (IOSRJEN), ISSN: 2278-8719, Vol. 3, Issue 7, ||V6 || PP 51-57.

A. Almeida, L. Moreira, J. Delgado (2013), Power Quality Problems and New Solutions, ISR Department of Electrical and Computer Engineering University of Coimbra, PloII, 3030-290 Coimbra (Portugal), Accessed on August 2014, pp. 1-9.

Shingare Prashant, (May 2014), Wind Turbine Control Systems Theory and Practices, Invited Technical Talk at one week workshop on, Passivity Based Control New Vistas, held at VJTI, Mumbai during 19-23 May 2014.

W. Deng, W. Pei (April 2008), Impact and improvement of distributed generation on voltage quality in micro-grid, Third International Conference on Electric Utility Deregulation and Restructuring and Power Technologies, pp.1737-1741.

E. Hayden, (2013) Introduction to microgrids, Securicon, LLC, 5400 Shawnee Road, Suite 206, Alexandria, Virginia 22312 USA, pp.1-13.

Gungor V., Hancke G., Buccella C., (Nov 2011). Smart Grid Technologies: Communication Technologies and Standards, IEEE Trnsaction on Industrail Informatics, VOL. 7, N0. 4, pp.529-539.

NIST (2010), NIST Framework and Roadmap for Smart Grid Interoperability Standards, Release 1.0. U.S. Department of Commerce, Gary Locke, Secretary, pp.1-145.

Daily wind data, Agricultural Meteorology Division, India Meteorological Department (IMD), June 2015, www. imdagrimet.gov.in

Leao R.P.S, Almada J.B., P.A. Souza, R.J. Cardoso, R.F. Sampaio F.K.A. Lima, Silveira J.G. and Formiga L.E.P. (2011), The Implementation of the Low Voltage Ride-Through Curve on the Protection System of a Wind Power Plant, International Conference on Renewable Energies and Power Quality (ICREPQ11), pp. 1-6.

Malia S., S. Jamesb, I. Tankb (2013), Improving low voltage ride-through capabilities for grid connected wind turbine generator, 4th International Conference on Advances in Energy Research 2013, Elsevier, ScienceDirect, Energy Procedia 54, pp. 530 - 540.

J. Dirksen, (2013), LVRT: Low Voltage Ride-Through, DEWI Magazin No. 43, August 2013, pp. 56-60.

Gehlhaar T, (2010), Grid Code Compliance beyond simple LVRT, Germanischer Lloyd Industrial Services, GmbH Competence Centre Renewable Certification, Hamburg, Germany [Online], pp 1-3. 